\title{
Digital plant: methods of discrete-event modeling and optimization of production characteristics
}

\author{
Valery L. Makarov ${ }^{\mathrm{a}}$ \\ E-mail:makarov@cemi.rssi.ru
}

\section{Albert R. Bakhtizin ${ }^{2}$}

E-mail: albert@cemi.rssi.ru

\section{Gayane L. Beklaryan ${ }^{\mathrm{a}}$}

E-mail: glbeklaryan@gmail.com

\section{Andranik S. Akopov ${ }^{\mathrm{b}, \mathrm{a}}$ (1)}

E-mail: aakopov@hse.ru

${ }^{\mathrm{a} C}$ Central Economics and Mathematics Institute, Russian Academy of Sciences

Address: 47, Nakhimovsky Prospect, Moscow 117418, Russia

${ }^{\mathrm{b}}$ National Research University Higher School of Economics

Address: 20, Myasnitskaya Street, Moscow 101000, Russia

\begin{abstract}
This article presents a new approach to the development of a 'digital twin' of a manufacturing enterprise, using a television manufacturing plant as the case study. The feature of the proposed approach is the use of hybrid methods of agent-based modeling and discrete-event simulation in order to implement a simulation model of a complex production process for assembling final products from supplied components. The most important requirement for such a system is the integration of all key chains of a digital plant: conveyor lines, warehouses with components and final products (TVs), sorting and conveyor system, assembly unit, technical control department, packing unit, etc. The proposed simulation model is implemented in the AnyLogic system, which supports the possibility of using agent-based and discrete-event modeling methods within one model. The system also supports using
\end{abstract}


the built-in genetic algorithm to optimize the main parameters of the model: the most important production characteristics (for example, assembly time of a product, the number of employees involved in assembly, quality control and packaging processes). Optimization experiments were completed with the help of the developed model at various intensities of loading conveyor lines with components, various restrictions on labor resources, etc. Three scenarios of the production system behavior are investigated: the absence of the components deficit with the possibility of significantly increasing the labor resource involved, a components deficit while demand for final products is maintained, and the presence of hard restrictions on the number of employees who can be involved in the processes under conditions of components deficit.

Key words: digital plant; production processes; agent-based modeling; discrete-event simulation; genetic algorithm; AnyLogic.

Citation: Makarov V.L., Bakhtizin A.R., Beklaryan G.L., Akopov A.S. (2021) Digital plant: methods of discrete-event modeling and optimization of production characteristics. Business Informatics, vol. 15, no 2, pp. 7-20. DOI: 10.17323/2587-814X.2021.2.7.20

\section{Introduction}

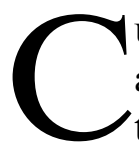
urrently, the problem of rational management of production characteristics in a dynamically changing external environment is becoming highly timely for many industrial enterprises (e.g. in conditions of a sharp decrease in the supply of components, significant increase in the cost of raw materials, lack of labor resources). At the same time, the complexity of production and logistics processes often does not allow enterprises to quickly adapt due to the operational management of their own resources (e.g. to reduce the volume of production without reducing labor resources, change the structure of the production portfolio without significant capital investments). The reason of emerging problems, as a rule, is the unbalanced state of various parts of the production chain (e.g. the deficit of production capacity with a significant turnover rate of warehouse stock). Therefore, there is a need to develop decision-making systems (DMS) based on the construction of 'digital twins' of enterprises. Such twins help to determine the best values of the characteristics of the production process in various scenario conditions (e.g. with a sharp change in demand for final products when there are interruptions with supplies of raw materials and components).

The first works devoted to the problems of rational production planning date back to the mid-20th century. It is necessary to highlight the most important works on rational organization of production activities using the methods of system dynamics [1, 2]. Also, well-known developments of the application of queuing systems theory (QS) [3, 4] to control complex production and logistics processes $[5,6]$. The central problem of such methods, developed within the framework of the well-known scientific field of operations research [7], is to optimize the characteristics of the chains for creating the final product. Examples include minimizing costs, maximizing the rate of turnover of stock, optimizing the number and structure of labor resources involved, as well as providing the required quality level and timeliness of finished goods delivery [8].

In modern times, we have methods of system dynamics [9-11], agent-based modeling [1214], discrete-event modeling [15, 16], heuristic optimization methods for a class of genetic algo- 
rithms [17-19] and others. For instance, a simulation model of a vertically integrated oil company, which includes the links of oil production, oil refining, transportation and sales, developed using the methods of system dynamics, is presented in [10]. The advantage of this model is the ability to maximize the shareholder value of an oil company under multiple constraints and take into account the influence of the feedback system arising in the value chain.

The next stage in the development of such intelligent production systems is the creation of so-called 'digital twins' [20-24] which are based on simulation models aggregated with databases, data warehouses, optimization modules, etc. For instance, a 'digital twin' of an organisation providing financial services is presented in [20], a simulation model of a mining enterprise is proposed in [21], implemented in the Powersim system.

This article develops a methodology for developing 'digital twins' of a manufacturing enterprise based on the methods of discreteevent and agent-based modeling with implementations in the AnyLogic system [25]. A new simulation model of the 'digital plant' type is proposed with the use of an enterprise that assembles TVs as the case study. The most important parameters of the production system are optimized according with the criteria of the value of the accumulated gross profit at the various scenario conditions.

\section{Digital factory concept}

Currently, TVs are assembled with the use of ready-made components, the production of which is done at other enterprises using an imported electronic component base (e.g. microprocessors, LCD displays, etc.) at most Russian plants. Despite certain disadvantages (such as complete dependence on the supply of imported components), such an organization of the production process can significantly reduce operating costs, mainly by attracting less expensive (local) labor, minimizing transport and tax costs.

The conceptual model of a 'digital plant' is based on the creation of a number of interacting subsystems, among which the most important are the following:

- simulation modeling subsystem, providing the ability to calculate the production and financial characteristics of the enterprise, taking into account the detailing of the entire chain of creating the final product for management at the micro level. The simulation model of an enterprise assembling TVs consists of the following important elements:

1. sources of component supplies required for the assembly of the final product (in particular, such components include housings, LCD screens, motherboards, video adapters, image processing units, power supplies, etc.) supplied to the factory in accordance with a given intensity;

2. warehouses of components which are intended for temporary storage of intermediate products (parts) and their delivery to conveyor lines;

3. sorting and conveyor system, designed for automatic synchronization of streams with components having different technical and operational characteristics, e.g. different size of the liquid crystal screen (in particular, varying from 20 to 90 inches), different body sizes, etc.;

4. assembly unit ensuring the assembly of final products using the attracted specialists (labor resources);

5. technical control unit providing quality control of the final product (testing devices);

6. packing unit performing the function of packing, picking and forming batches of final products;

7. warehouse of final products that is intended for temporary storage of TVs;

8. shipping unit providing the function of shipment of batches of final products by transferring it to a transport company; 
- data warehouse, intended for storing the initial data required for simulation modeling and processing the results of optimization experiments;

- optimization module aggregated through objective functions with the simulation model of the enterprise and providing the ability to search for the best values of the characteristics of the production process in various scenario conditions.

An aggregated diagram of the 'digital twin' of an enterprise assembling TVs is shown in Figure 1.

Note that an important feature of the system under consideration (Figure 1) is the presence of agents involved in the production process: agents-components with their own individual characteristics;

agents-products variated by their functional characteristics (e.g. TV model, matrix size, cost, etc.);

agents-batches of final products, which are a grouping of agents-products (by TVmodels) for transportation.

- agents-resources (humans) involved in various processes (e.g. assemblers, quality control specialists, packers, etc.).

At the same time, the production system provides a mechanism for automatic transformation of agents-components into final agentsproducts, as well as grouping of agents-products in the form of batches of final products (TVs).

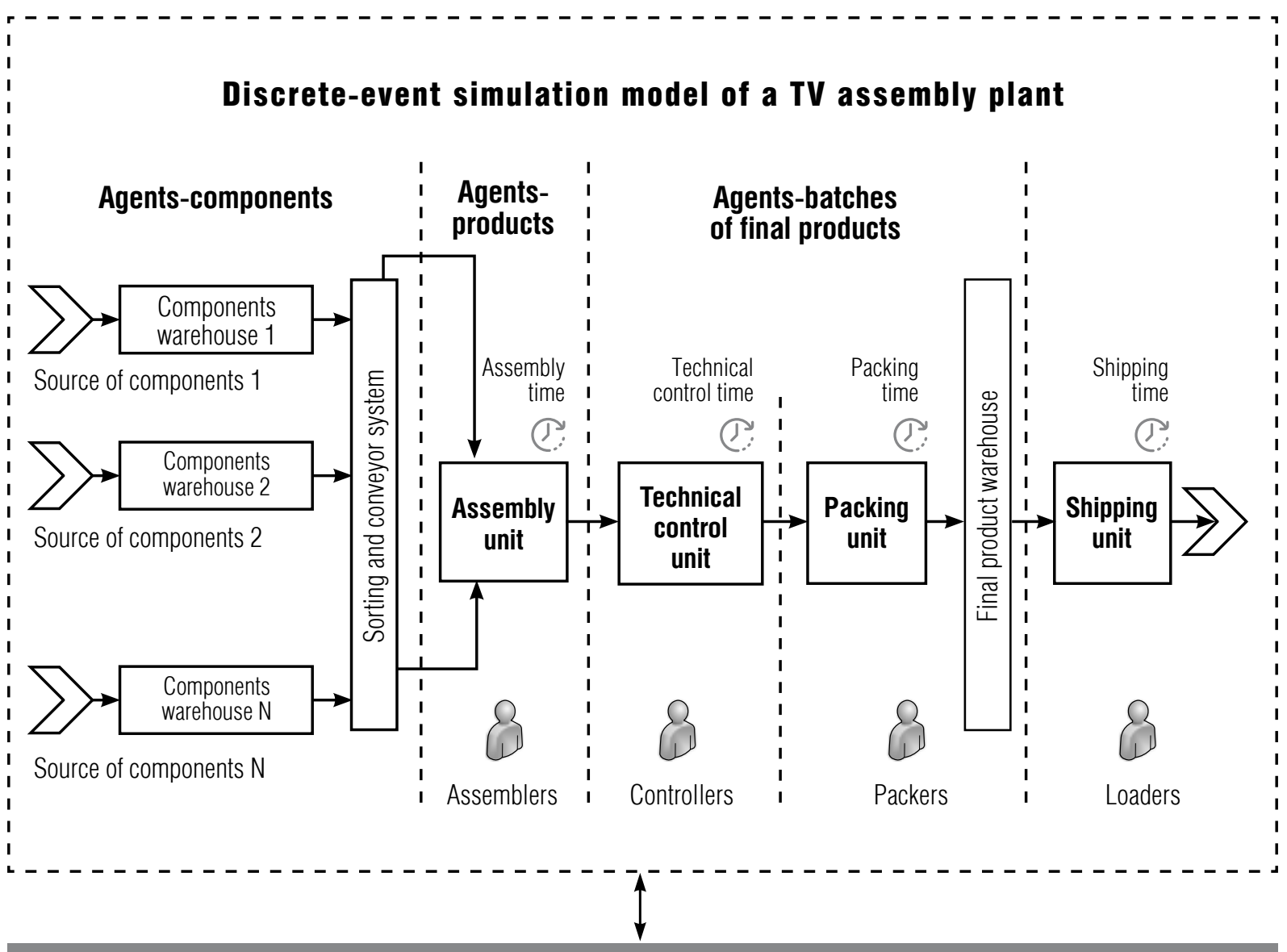

\section{Data warehouse}

Fig. 1. Aggregated diagram of the 'digital twin' of a manufacturing enterprise 


\section{Simulation model}

Earlier, a simulation model of an assembly unit implemented in the AnyLogic system was presented in [21]. Such a model can be considered as a prototype when creating a more complex model of a hybrid type which simultaneously uses the methods of system dynamics, agent-based and discrete-event modeling. Another important difference of the model proposed here is a more complex structure and dynamics of supply of components, characterized by the presence of multiple time gaps. At the same time, the main service characteristics of the production process (in particular, the time of assembly, technical control, shipment, etc.), which significantly affect its effectiveness, are stochastic. As a result, the performance metric of such a system (profit dynamics) belongs to the class of multimodal objective functions with multiple break points, the maximization of which cannot be performed by known analytical methods. Therefore, in order to create a 'digital twin' of a production enterprise that assembles TVs, an original simulation model is being developed, aggregated by target functionality with a built-in genetic algorithm that provides the search for the best solutions based on heuristics.

Further, a brief problem statement of optimizing main characteristics of the considered manufacturing enterprise is given.

Here:

- $t_{r} \in T-$ is the discrete model time; $T=\left\{t_{1}, t_{2}, \ldots, t_{|T|}\right\}$ - a set of moments of model time; $|T|$ - the total number of moments of model time;

- $I=\left\{i_{1}, i_{2}, \ldots, i_{|I|}\right\}-$ is the set of indices of models of the assembled TVs (variable by the screen size, different functional characteristics, etc.); $|I|-$ is the total number of assembled TV-models;

- $J_{i}=\left\{j_{i_{1}}, j_{i_{2}}, \ldots, j_{\left|J_{i}\right|}\right\}, i \in I-$ is the set of indices of components required for assembly $i$-th television model (e.g. bodies, LCD screens, system boards, etc.); $\left|J_{i}\right|-$ is the total number of components that are necessary for assembling TV sets of $i$-th type;

- $\left\{n_{1}, n_{2}, \ldots, n_{N}\right\}-$ is the number of specialists of various categories (e.g. assemblers of the first and second qualification levels, QMspecialists, packers and loaders) involved in production processes, humans; $N$ is the total number of qualification categories of employees; $\xi=\{1,2, \ldots, N\}-$ is index of the category of employees and the types of processes in which they are involved;

- $\left\{w_{1}\left(t_{r}\right), w_{2}\left(t_{r}\right), \ldots, w_{N}\left(t_{r}\right)\right\}, t_{r} \in T-$ are the daily salaries of specialists of various categories involved in production processes, rubles;

- $c_{j_{i}}\left(t_{r}\right), j_{i} \in J_{i}, i \in I, t_{r} \in T$ - is the cost of components required for assembly the $i$-th TV model at the moment $t_{r}$, rubles;

- $p_{i}\left(t_{r}\right), i \in I, t_{r} \in T-$ is the price of a final pro$\operatorname{duct}(\mathrm{TV})$ at the moment $t_{r}$, rubles;

- $\left\{\tau_{1}, \tau_{2}, \ldots, \tau_{N}\right\}-$ the average time for assembling a final product from main and auxiliary parts, technical control time, packing and shipping times per employee involved in the relevant operations;

- $\delta_{j_{i}}\left(t_{r}\right), j_{i} \in J_{i}, i \in I, t_{r} \in T$ - is the endogenous structure of supply of components at the moment $t_{r}$, specified using a unit impulse function with random arguments, items;

- $v_{i}\left(t_{r}\right), i \in I, t_{r} \in T-$ is the endogenous structure of final product output at the moment determined as a result of simulation and depending on the sets of control parameters $\left\{n_{1}, n_{2}, \ldots, n_{N}\right\},\left\{\tau_{1}, \tau_{2}, \ldots, \tau_{N}\right\}$, as well as the dynamics of supply of components $\delta_{j_{i}}\left(t_{r}\right)$, items.

Daily gross profit of the enterprise at the moment $t_{r}, t_{r} \in T$ :

$$
\begin{gathered}
\pi\left(t_{r}\right)=\sum_{i=1}^{|I|}\left(\left(v_{i}\left(t_{r}\right) p_{i}\right)\left(t_{r}\right)-\sum_{j_{i}=1}^{\left|J_{i}\right|} \delta_{j_{i}}\left(t_{r}\right) c_{j_{i}}\left(t_{r}\right)\right)- \\
-\sum_{\xi=1}^{N} w_{\xi}\left(t_{r}\right) n_{\xi} .
\end{gathered}
$$


Now we can formulate the central task of the manufacturing enterprise to maximize the accumulated gross profit.

The problem. The need to maximize the accumulated gross profit by sets of control parameters $\left\{n_{1}, n_{2}, \ldots, n_{N}\right\}$ and $\left\{\tau_{1}, \tau_{2}, \ldots, \tau_{N}\right\}$ :

$$
\sum_{t_{r}=1}^{|T|} \pi\left(t_{r}\right) \rightarrow \max _{\left\{n_{1}, n_{2}, \ldots, n_{5}\right\},\left\{\tau_{1}, \tau_{2}, \ldots, \tau_{5}\right\}},
$$

s.t.

$$
\underline{n}_{\xi} \leq n_{\xi} \leq \bar{n}_{\xi}, \underline{\tau}_{\xi} \leq \tau_{\xi} \leq \bar{\tau}_{\xi}
$$

Here $\left\{\underline{n}_{\xi}, \bar{n}_{\xi}\right\},\left\{\underline{\tau}_{\xi}, \bar{\tau}_{\xi}\right\}$ are known boundary values of control parameters (upper and lower limits).

The proposed simulation model that provides the computation of the objective function (1)-(2) was implemented in the AnyLogic system (Figure 2). The main feature of the model is the high dimensionality of initial data flows (tens thousands of components involved in the assembly of TVs with their individual characteristics). In particular, it is determined by the presence of a large number of elements of a 'warehouse' type used for storing intermediate and final products, and also the use of sorting and conveyor systems for synchronizing the flows of agents-components (Figure 2).

Another important feature of the model shown in Figure 2 is the integration of the module of computing financial and economic indicators with operational submodels. These sub-models implement the processes of receiving and distributing components through sorting and conveyor systems, assembly unit, technical control unit, packaging and formation of batch units vary-
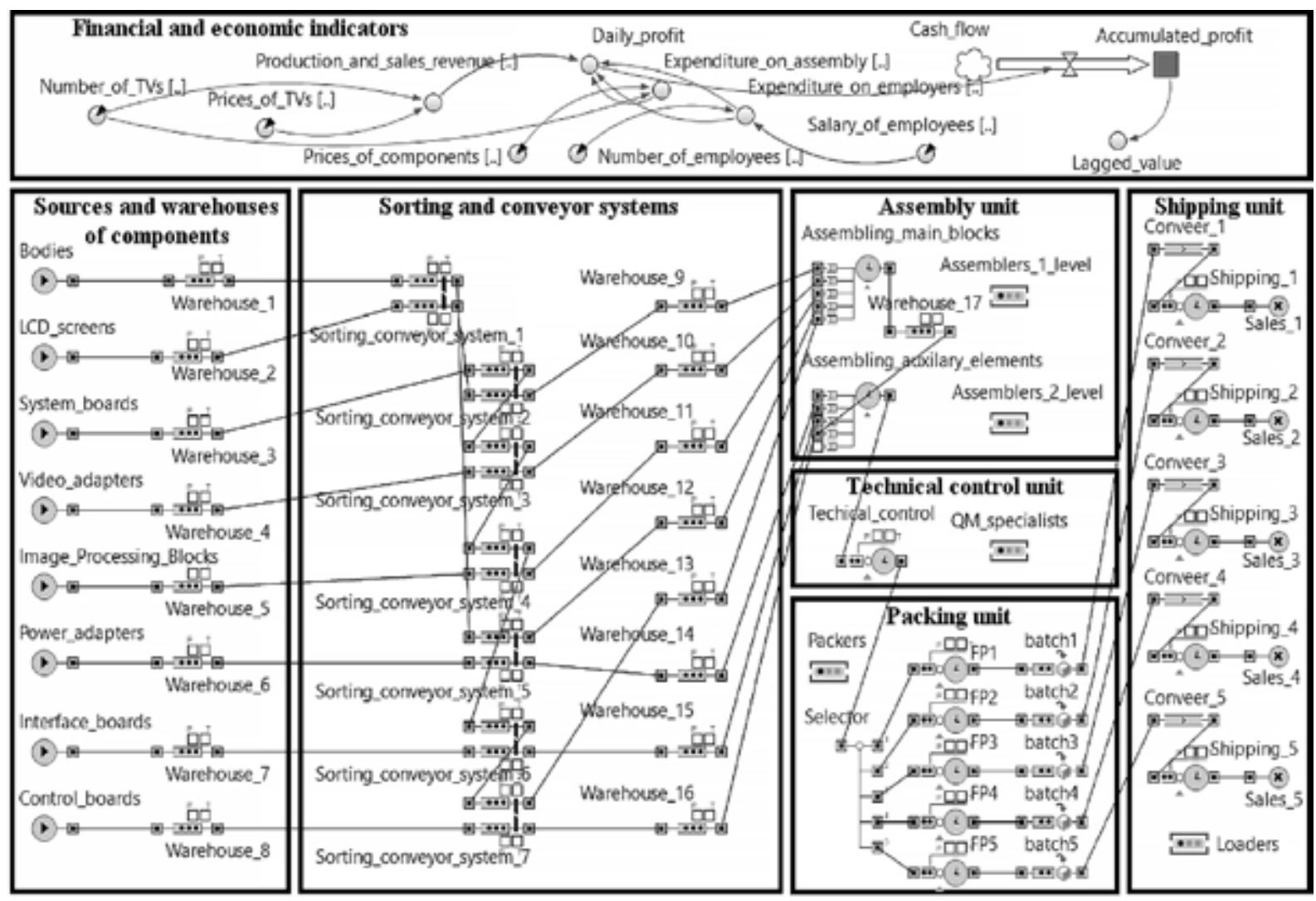

Fig. 2. Simulation model of TV equipment manufacturing plant in AnyLogic 
ing by a product type (e.g. depending on the size of the LCD screen and the specified set of functions). The initial data of component (characteristics of elements) are loaded from the system database taking into account a variable number of each type elements, simultaneously arriving in accordance with a given intensity. The software implementation of the simulation model was performed using the Java programming language supported in the AnyLogic system.

To start sequential processing of components in the model, a special object of the source type (component source) is used in which the characteristics of each generated agent belonging to the Components_X class (components of type $\mathbf{X}$ ) are redefined in a special field - 'Actions when approaching the exit':

$(($ Components_X $)$ entity $)$.parameter $=$ components_X.get (index_X) .parameter;

index_X $=$ index_X ++ ;

Here, Components_X is a population of component agents of type $\mathbf{X}$ with characteristics whose values are dynamically loaded from the data warehouse (MS SQL Server), parameter is one of the possible parameters of the component agent ((Components_X) entity), e.g. the overall size of the body, index_X is the global variable used as an iterator to access the next member of the Components_X population (i.e. the agent-component). Note that starting with the AnyLogic of version 8, the simpler form of access to data of an agent participating in the process chain is supported using the agent attribute instead of the ((Components_X) entity). At the same time, when creating multiple requests, the 'Actions when approaching the exit' method is also performed multiple times for each component agent outgoing from the source (Figure 3). The number of agents- components generated at any given time is set by means of a single impulse function with random arguments determining the expected number of details that will arrive in the case of the arrival of a given batch:

(int) pulse(uniform $(0,100)$, uniform $(0,100))^{\star}$ uniform_ $\operatorname{discr}(1000,1500)$;

Also, one of the most important elements of the proposed model is the formation of batches of final products by distributing the flow of TVs that have passed technical control into groups depending on the type of an agent-product (i.e. a model of TV) (Figure 4).

Because of the prices of the final products depend on the model range of the assembled TVs, computing the revenue and expenditure is possible to use indicators whose values are calculated in the elements of the process diagram (Figure 2), e.g. the number of assembled TVs of various types can be set as follows:

Number_TV.set (Implementation1.count () * batch1_ size, $\mathrm{M})$;

Here, Implementation1.count () is the function that computes the number of elements (agents-products of the first type) at the exit from the production process, batch1_size is the number of products in a batch, $\mathbf{M}$ is the index of TV-model.

\section{Experimental results}

As mentioned earlier, the sources of suppling agents-components provide the generation of the components required for assembly using a single impulse function with stochastic arguments. Figure 5 shows the dynamics of such deliveries over the model time interval from 1 to 100 days. 


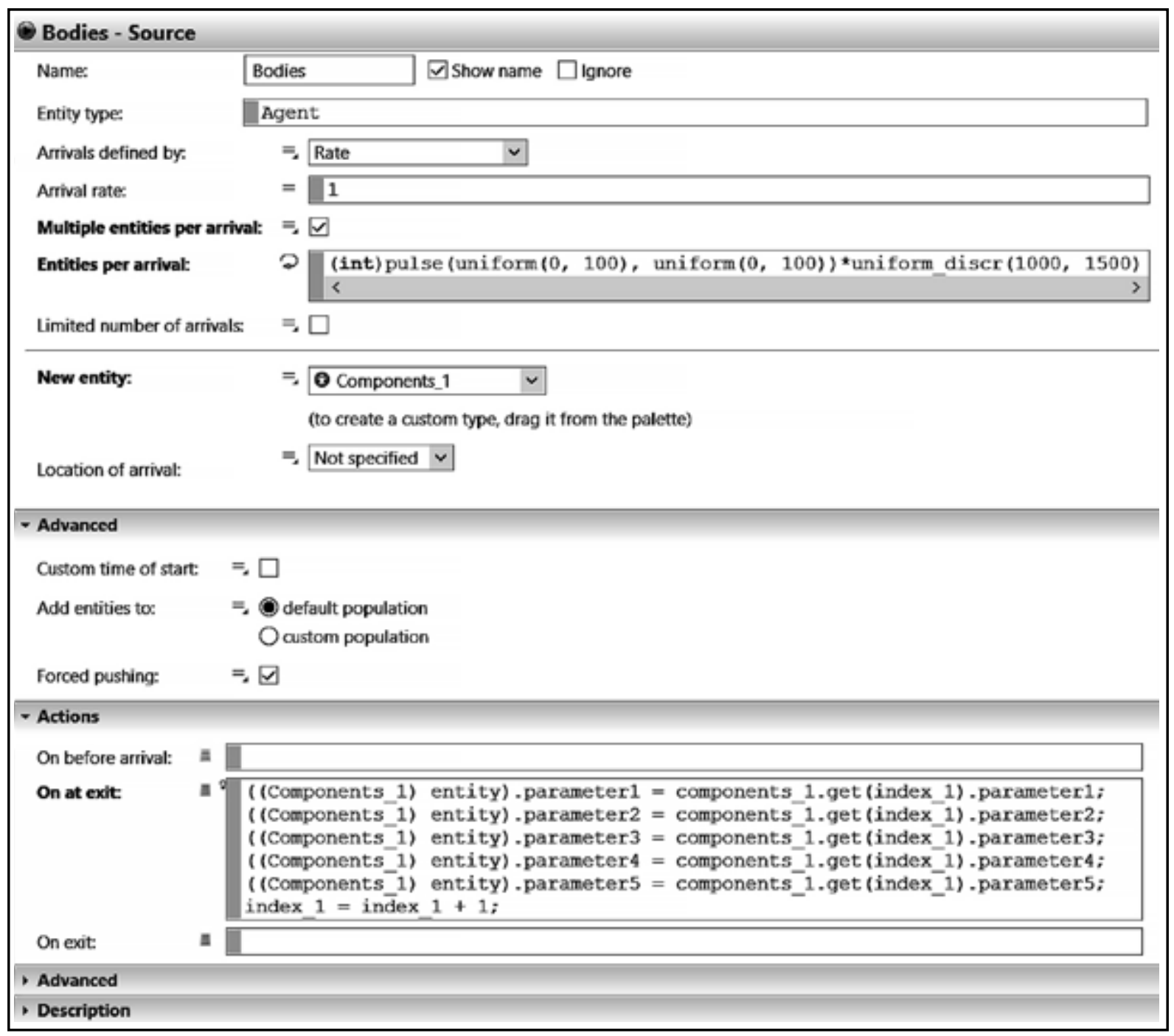

Fig. 3. Properties of a typical source of supply of agent-components

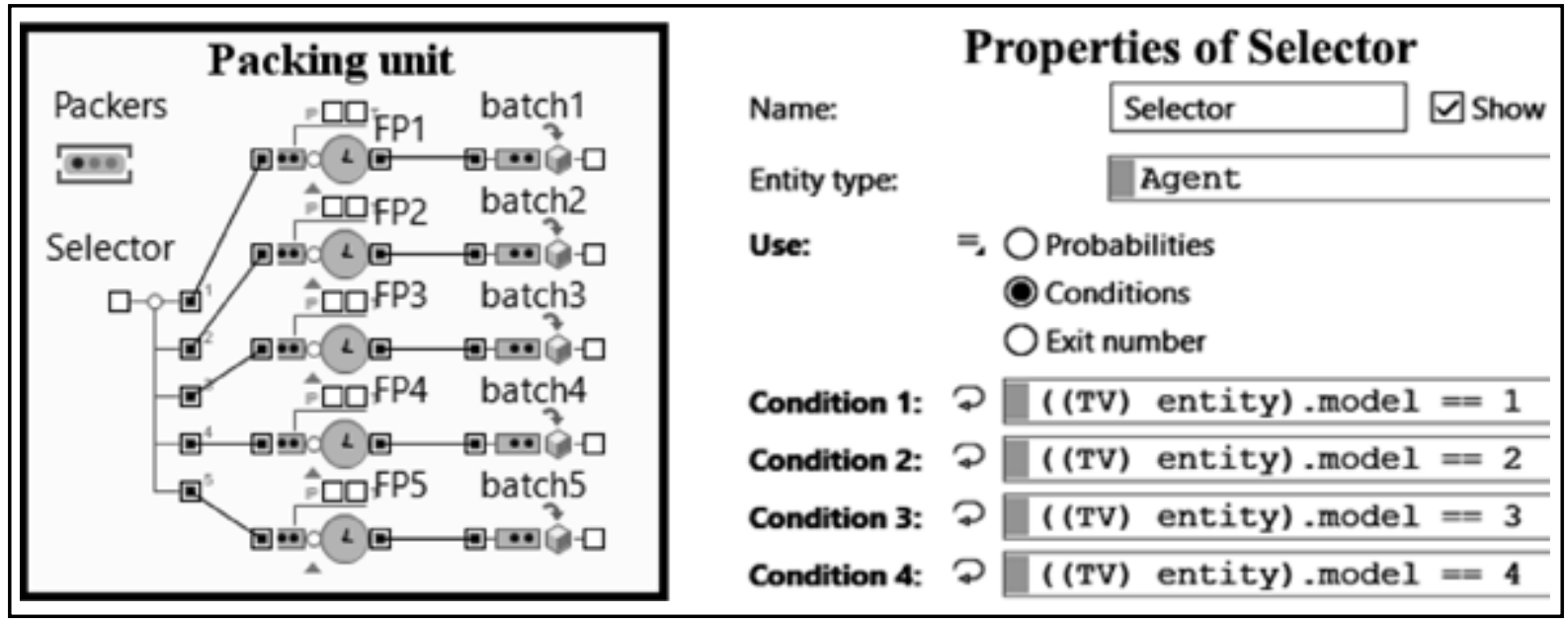

Fig. 4. Distribution of the flow of final products when forming batches 

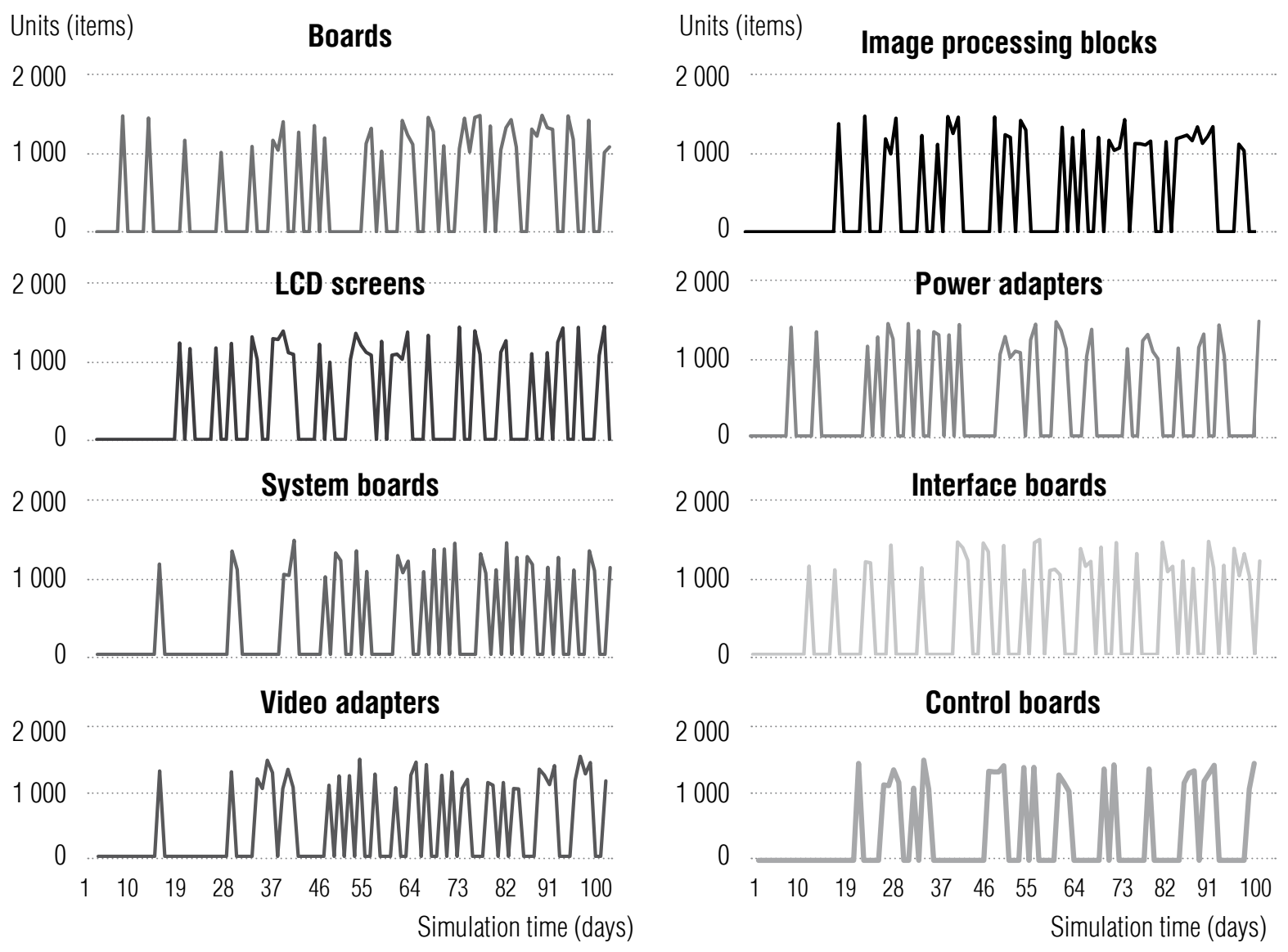

Fig. 5. Model dynamics of supplying the components

As follows from Figure 5, there are time gaps between component supplies due to natural logistic disruptions. Therefore, the model provides automatic synchronization of input flows through sorting and conveyor systems that redirect selected and mutually matched elements to the assembly unit.

Figure 6 shows the model dynamics of warehouse stocks of main and auxiliary assemblies, as well as finished products (TVs).

Further, optimization experiments were carried out aimed at maximizing the profit generated because of the assembly and sale of TVs. Optimization experiments were performed using the genetic algorithm embedded in the AnyLogic. At the same time, the following control parameters of the model were selected as decision variables:

- number of agents-assemblers (humans) of various categories involved in the assembly of main and auxiliary parts;

- number of quality control agents responsible for performing technical control of final products (TVs);

- number of agents-packers and agentsloaders involved in the processes of packaging and shipment of final products, respectively;

- average (median) values of assembly time, technical control time, packaging and shipment (sale) times affecting the speed of execution of the corresponding processes. 


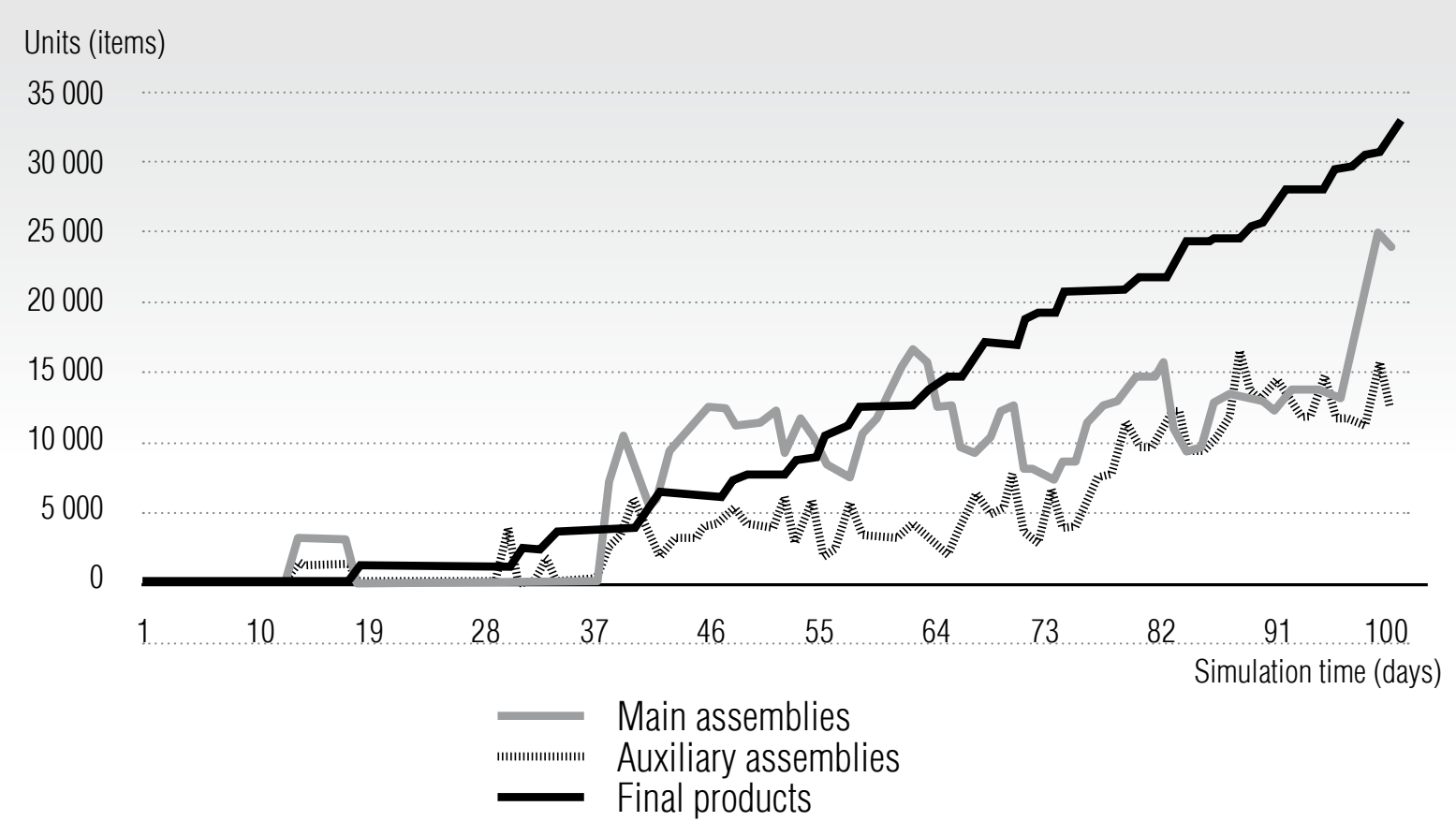

Fig. 6. Model dynamics of warehouse stocks

Accumulated profit (mln rubles)

700

600

500

400

300

200

0

$-100$

$\begin{array}{lllllllllllll}-200 & 1 & 10 & 19 & 28 & 37 & 46 & 55 & 64 & 73 & 82 & 91 & 100\end{array}$

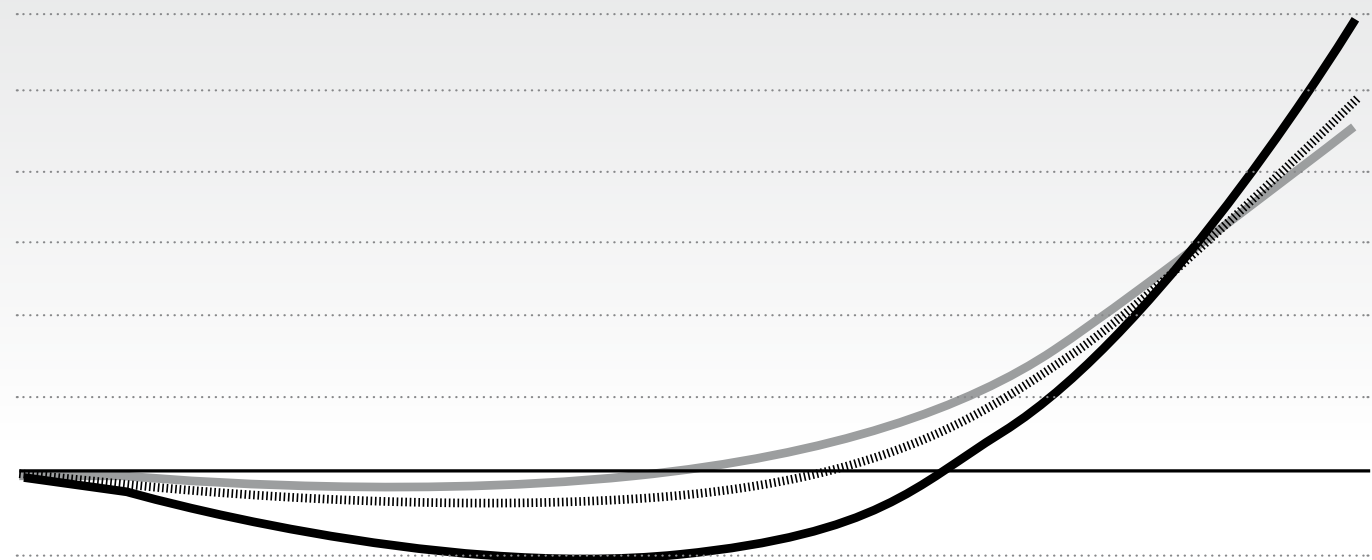

Simulation time (days)

- Scenario 1. Without components and labor resources deficit

"umumumum Scenario 2. Deficit of components Scenario 3. Hard resource restrictions

Fig. 7. Results of optimization experiments (accumulated profit) 
Values of the sought variables and optimization results

Table 1.

\begin{tabular}{l|c|c|c}
\hline \multicolumn{1}{c|}{ Model parameter } & $\begin{array}{c}\text { Scenario 1: } \\
\text { Without deficit } \\
\text { of components } \\
\text { and labor resources }\end{array}$ & $\begin{array}{c}\text { Scenario 2: } \\
\text { Deficit } \\
\text { of components }\end{array}$ & $\begin{array}{c}\text { Scenario 3: } \\
\text { Hard resource } \\
\text { restrictions }\end{array}$ \\
\hline $\begin{array}{l}\text { Number of agents-assemblers of the 1st category, } \\
\text { people }\end{array}$ & 1000 & 430 & 125 \\
\hline $\begin{array}{l}\text { Number of agents-assemblers of the 2nd cat- } \\
\text { egory, people }\end{array}$ & 500 & 225 & 84 \\
\hline $\begin{array}{l}\text { Number of agents- specialists belong to technical } \\
\text { control department, people }\end{array}$ & 100 & 30 & 15 \\
\hline $\begin{array}{l}\text { Number of agents- packers, people } \\
\text { Number of agents-loaders, people }\end{array}$ & 100 & 27 & 13 \\
\hline Average assembly time, days & 50 & 0.05 & 0.03 \\
\hline Average technical control time, days & 0.01 & 0.01 & 0.008 \\
\hline Average packing time, days & 0.01 & 0.07 & 0.05 \\
\hline Average shipping time, days & 7 & 594 & 468 \\
\hline $\begin{array}{l}\text { Accumulated gross profit at time T=100, } \\
\text { million rubles }\end{array}$ & 619 & 20 \\
\hline
\end{tabular}

At the same time, three scenarios of the behavior of the considered production system were considered:

Scenario 1. Without any deficit of components and with the possibility of a significant increase in the involved labor resources.

Scenario 2. A deficit of components while demand for final products is maintained

Scenario 3. The presence of hard resource restrictions on the number of employees involved in the processes while many of the needed components are missing.
In Figure 7 the results of optimization experiments are shown.

Table 1 shows the numerical values of the sought variables obtained because of optimization for the three considered scenarios of the behavior of the investigated production system.

As follows from Figure 7 and Table 1, the use of a genetic algorithm to optimize the characteristics of the developed discrete-event simulation model made it possible to determine the best (suboptimal) values of the decision-variables corresponding to three fundamentally different scenarios of the production system 
behavior. At the same time, the dynamics of the accumulated gross profit is generally stable in relation to the scenarios under study. Thus, for instance, in conditions of components deficit (Scenario 2) due to a significant reduction in the number of involved labor resources with a simultaneous decrease in the execution time of production operations (i.e. due to increasing labor productivity), a significant level of accumulated profit can be ensured. In addition, the same financial result can be obtained in conditions of hard resources restrictions and the absence of the components deficit (Scenario 3).

\section{Conclusion}

This article presents a new approach to the development of a 'digital twin' of a manufacturing enterprise (using a TVs assembly plant as the case study) based on the combined use of discrete-event and agent-based simulation methods. A conceptual model of a digital plant is proposed with subsequent software implementation in the AnyLogic simulation system. We formulated and solved the most important problem of maximising the gross accumulated profit of a manufacturing enterprise taking into account the contribution of the operational component, including the dynamics of the volume of finished products, the number of employees involved in various processes, the execution time of production operations, etc.
Numerical studies were completed, in particular, optimization experiments which confirm the possibility of determining the best solutions that ensure the stability of the accumulated gross profit of the enterprise in relation to various characteristics of the external environment (e.g. in conditions of the components deficit and hard resource restrictions).

The simulation results demonstrate the possibility of obtaining an accumulated gross profit of the manufacturing plant that is stable in relation to the scenario characteristics of environment. Thus, for instance, in the appearance of the components deficit (Scenario 2), as well as in conditions of hard resource constraints and the absence of the components deficit (Scenario 3), it is possible to provide a level of accumulated profit close to the financial result of the first scenario with the absence of such restrictions.

Further research will focus on the development of methods for the creating 'digital twins' of manufacturing enterprises with a more complex organizational structure and nested (hierarchical, multilevel) processes.

\section{Acknowledgments}

This study was funded by the Russian Foundation for Basic Research (RFBR) under the research project No 18-29-03139.

\section{References}

1. Forrester J.W. (1961) Industrial dynamics. MIT Press.

2. Sterman J.D. (2000) Business dynamics: Systems thinking and modeling for a complex world. McGraw Hill.

3. Saaty T.L. (1983) Elements of queuing theory with applications. Dover Pubns.

4. Sundarapandian V. (2009) Probability, statistics and queueing theory. PHI Learning.

5. Rashid R., Hoseini S.F., Gholamian M.R, Feizabadi M. (2015) Application of queuing theory in production-inventory optimization. International Journal of Industrial Engineering, no 11, pp. 485-494. DOI: $10.1007 / \mathrm{s} 40092-015-0115-9$.

6. Marsudi M., Shafeek H. (2013) Production line performance by using queuing model. Proceedings of the 7th IFAC Conference on Manufacturing Modelling, Management, and Control, Saint Petersburg, Russia, 19-21 June 2013, vol. 46, no 9, pp. 1152-1157.

7. Wetherbe J.C. (1979) Systems analysis for computer-based information systems. West Publishing. 
8. Robinson S. (2004) Simulation: The practice of model development and use. Wiley.

9. Akopov A.S., Khachatryan N.K. (2014) System dynamics. Moscow: CEMI RAS (in Russian).

10. Akopov A.S. (2012) Designing of integrated system-dynamics models for an oil company. International Journal of Computer Applications in Technology, vol. 45, no 4, pp. 220-230. DOI: 10.1504/IJCAT.2012.051122.

11. Beklaryan G.L., Akopov A.S., Khachatryan N.K. (2019) Optimisation of system dynamics models using a real-coded genetic algorithm with fuzzy control. Cybernetics and Information Technologies, vol. 19, no 2, pp. 87-103. DOI: 10.2478/cait-2019-0017.

12. Akopov A.S., Khachatryan N.K. (2016) Agent-based modeling. Moscow: CEMI RAS (in Russian).

13. Bakhtizin A.R. (2008) Agent-based models of the economy. Moscow: Economics (in Russian).

14. Akopov A.S., Beklaryan L.A., Saghatelyan A.K. (2019) Agent-based modelling of interactions between air pollutants and greenery using a case study of Yerevan, Armenia. Environmental Modelling and Software, no 116, pp. 7-25. DOI: 10.1016/j.envsoft.2019.02.003.

15. Akopov A.S. (2017) Simulation modeling. Moscow: Urait (in Russian).

16. Tang J., Leu G., Abbass H.A. (2020) Discrete event simulation. Simulation and Computational Red Teaming for Problem Solving. IEEE, pp. 121-142.

17. Akopov A.S., Beklaryan L.A., Beklaryan A.L. (2020) Cluster-based optimization of an evacuation process using a parallel bi-objective real-coded genetic algorithm. Cybernetics and Information Technologies, vol. 20, no 3, pp. 45-63. DOI: 10.2478/cait-2020-0027.

18. Akopov A.S., Beklaryan L.A., Thakur M., Verma D.B. (2019) Parallel multi-agent real-coded genetic algorithm for large-scale black-box single-objective optimization. Knowledge-Based Systems, no 174, pp. 103-122. DOI: 10.1016/j.knosys.2019.03.003.

19. Akopov A.S. (2014) Parallel genetic algorithm with fading selection. International Journal of Computer Applications in Technology, vol. 49, no 3/4, pp. 325-331. DOI: 10.1504/IJCAT.2014.062368.

20. Makarov V.L., Bakhtizin A.R., Beklaryan G.L., Akopov A.S. (2019) Developing digital twins for financial organisations. Audit and Financial Analysis, no 5, pp. 38-45 (in Russian).

21. Makarov V.L., Bakhtizin A.R., Beklaryan G.L. (2019) Developing digital twins for production enterprises. Business Informatics, vol. 14, no 1, pp. 7-16. DOI: 10.17323/1998-0663.2019.4.7.16.

22. Saddik A.El. (2018) Digital twins: The convergence of multimedia technologies. IEEE MultiMedia, vol. 25, no 2, pp. 87-92. DOI: 10.1109/MMUL.2018.023121167.

23. Tao F., Sui F, Liu A., Qi Q., Zhang M., Song B., Guo Z., Lu S.C.-Y., Nee A.Y.C. (2018) Digital twin-driven product design framework. International Journal of Production Research, vol. 57, no 12, pp. 3935-3953. DOI: 10.1080/00207543.2018.1443229.

24. Xu Y., Sun Y., Liu X., Zheng Y. (2019) A digital-twin-assisted fault diagnosis using deep transfer learning. IEEE Access, no 7, pp. 19990-19999. DOI: 10.1109/ACCESS.2018.2890566.

25. Borshchev A. (2013) The Big Book of simulation modeling. Multimethod modeling with AnyLogic 6. AnyLogic North America.

\section{About the authors}

\section{Valery L. Makarov}

Dr. Sci. (Phys.-Math.); Academician of Russian Academy of Sciences;

Academic Supervisor, Central Economics and Mathematics Institute, Russian Academy of Sciences, 47, Nakhimovsky Prospect, Moscow 117418, Russia;

E-mail:makarov@cemi.rssi.ru

ORCID: 0000-0002-2802-2100 


\section{Albert R. Bakhtizin}

Dr. Sci. (Econ.); Corresponding Member of Russian Academy of Sciences;

Director, Central Economics and Mathematics Institute, Russian Academy of Sciences, 47, Nakhimovsky Prospect, Moscow 117418, Russia;

E-mail: albert@cemi.rssi.ru

ORCID: 0000-0002-9649-0168

\section{Gayane L. Beklaryan}

Cand. Sci. (Econ.);

Senior Researcher, Laboratory of Computer Modeling of Social and Economic Processes, Central Economics and Mathematics Institute, Russian Academy of Sciences, 47, Nakhimovsky Prospect, Moscow 117418, Russia;

E-mail: glbeklaryan@gmail.com

ORCID: 0000-0002-1286-0345

\section{Andranik S. Akopov}

Dr. Sci. (Tech.);

Professor, Department of Business Informatics, Graduate School of Business, National Research University Higher School of Economics, 20, Myasnitskaya Street, Moscow 101000, Russia;

Chief Researcher, Laboratory of Dynamic Models of Economy and Optimization, Central Economics and Mathematics Institute, Russian Academy of Sciences, 47, Nachimovky Prospect, Moscow 117418, Russia;

E-mail: aakopov@hse.ru 